Supporting Information for

\title{
Dispersion interactions enable the self-directed growth of linear alkane nanostructures covalently bound to silicon
}

Gino A. DiLabio, ${ }^{\dagger *}$ Paul G. Piva, ${ }^{\dagger \ddagger}$ Peter Kruse, ${ }^{\natural}$ and Robert A. Wolkow ${ }^{\dagger \neq *}$

National Institute for Nanotechnology, National Research Council of Canada, W6-010 ECERF 9107-116 ${ }^{\text {th }}$ Street, Edmonton, Alberta T6G 2V4 Canada and Department of Physics, University of Alberta, Edmonton, Alberta T6G 2J1 Canada
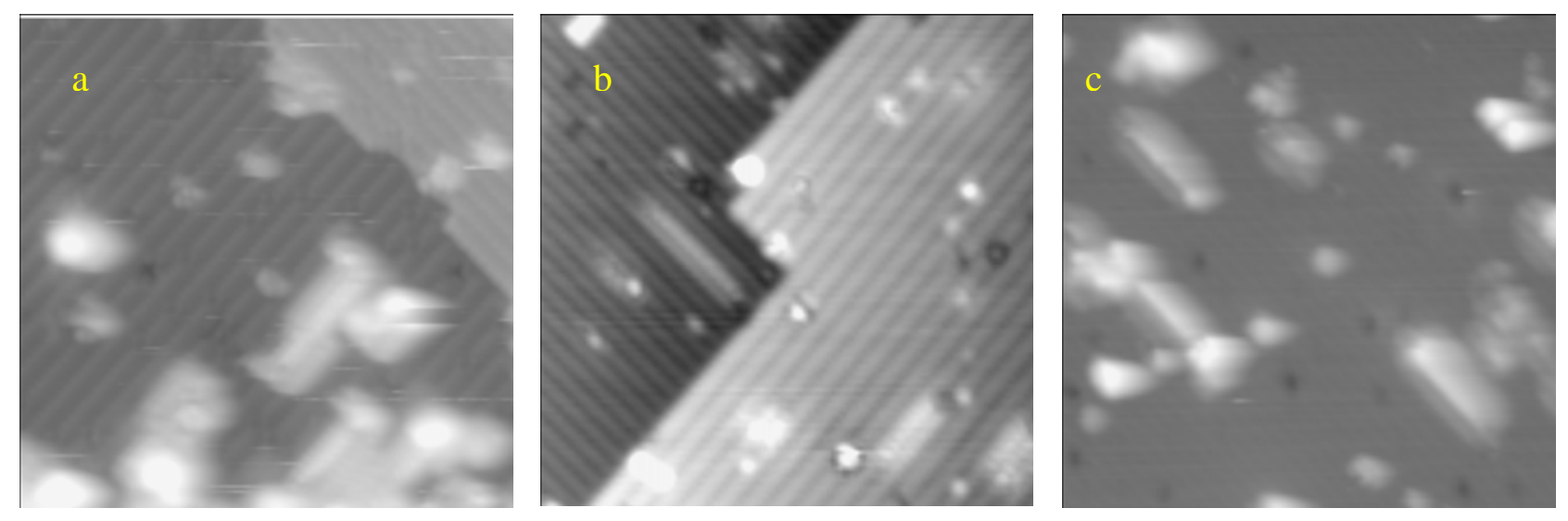

Figure S1. Scanning tunneling microscope images of molecular lines on n-doped $\mathrm{H}$ $\mathrm{Si}(100)$. a) 1-octene. Dose $=200 \mathrm{~L}$, Area $=(18.7 \mathrm{~nm})^{2}$, Vs $=+2.0 \mathrm{~V}$ Is $=40$ pA. Grey-scale: 0 to $0.78 \mathrm{~nm}$. b) 1-undecene. Dose $=10 \mathrm{~L}$, Area $=(20 \mathrm{~nm})^{2}, \mathrm{Vs}=+2.0 \mathrm{~V} \mathrm{Is}=40 \mathrm{pA}$. Greyscale: 0 to $0.30 \mathrm{~nm}$. c) 1-tetradecene. Dose $=80 \mathrm{~L}$, Area $=(25 \mathrm{~nm})^{2}, \mathrm{Vs}=-2.0 \mathrm{~V}$ Is $=40 \mathrm{pA}$. Grey-scale: 0 to $0.87 \mathrm{~nm}$ 